\title{
DESENVOLVIMENTO DE MUDAS DE MULUNGU FERTIRRIGADAS COM DIFERENTES SOLUÇÕES NUTRITIVAS
}

Antônio Lucieudo Gonçalves Cavalcante ${ }^{1}$, Francisco de Assis de Oliveira ${ }^{2 *}$, Kleane Targino Oliveira Pe reira ${ }^{1}$, Renata de Paiva Dantas ${ }^{1}$, Mychelle Karla Teixeira de Oliveira ${ }^{3}$, Rafaela Cristina da Cunha ${ }^{4}$, Maria Williane de Lima Souza $^{4}$

${ }^{1}$ Universidade Federal Rural do Semi-Árido, Curso de Engenharia Florestal, Mossoró, Rio Grande do Norte, Brasil - cieudo.eng@ gmail.com; kleane_m@hotmail.com; renatadepaiva@hotmail.com

${ }^{2}$ Universidade Federal Rural do Semi-Árido, Departamento de Ciências Ambientais e Tecnológicas, Mossoró, Rio Grande do Norte, Brasil thikaoamigao@ufersa.edu.br*

${ }^{3}$ Universidade Federal Rural do Semi-Árido, Departamento de Ciências Ambientais e Tecnológicas, Mossoró, Rio Grande do Norte, Brasil mymykar@gmail.com

${ }^{4}$ Universidade Federal Rural do Semi-Árido, Curso de Ciências Ambientais e Tecnológicas, Mossoró, Rio Grande do Norte, Brasil rafacris_dantas@hotmail.com; williane-lima@hotmail.com

Recebido para publicação: 21/12/2013 - Aceito para publicação: 18/11/2015

\begin{abstract}
Resumo
O mulungu (Erythrina vellutina Willd) é uma espécie nativa que ocorre em diversas regiões do país, com potencial para uso madeireiro, arborização urbana e para recomposição de vegetação em áreas degradadas. Contudo, ainda é uma espécie pouco estudada. O presente trabalho foi desenvolvido com o objetivo de avaliar o efeito de seis concentrações de nutrientes na solução de fertirrigação $(0,25,50,75,100$ e $125 \%)$, dispostos em delineamento experimental inteiramente casualizado, com três repetições. Foram realizados dois experimentos independentes, sendo um para cada acesso. As mudas foram avaliadas para as seguintes variáveis: altura, diâmetro do caule, número de folhas, área foliar, massa seca da parte aérea, massa seca da raiz e massa seca total, área foliar específica, razão de área foliar, relação altura/diâmetro e índice de qualidade de Dickson. Com exceção das variáveis área foliar específica e razão de área foliar, todas as demais foram afetadas pelos tratamentos aplicados para os dois acessos. Para ambos os acessos, mudas de melhor qualidade podem ser produzidas utilizando-se fertirrigação com solução nutritiva variando de 70 a $80 \%$ da solução padrão.

Palavras-chave: Erythrina vellutina Willd; viveiro florestal; nutrição mineral; índice de qualidade de Dickson.
\end{abstract}

\begin{abstract}
Development of seedlings mulungu fertigated with different nutrient solutions. The mulungu (Erythrina vellutina Willd) is a native species that occurs in various regions of the country, with potential for timber use, urban tree planting and restoration of vegetation in degraded areas, however, is still a little studied species. This work was to evaluate the effect of six nutrient concentrations in fertigation solution $(0,25,50,75,100$ and 125\%), arranged in a completely randomized design with three replications. Two independent experiments were performed, one for each access. The seedlings were evaluated for the following variables: height, stem diameter, number of leaves, leaf area, shoot dry weight, root dry mass and dry mass of the total, specific leaf area, leaf area ratio, height/diameter ratio and Dickson quality index. With the exception of the variables specific le af area and leaf area ratio, all other were affected by the treatments applied to the two hits. For both access, better quality seedlings can be produced using fertigation with nutrient solution ranging from 70 to $80 \%$ of the standard solution

Keywords: Erythrina vellutina Willd; forest nursery; mineral nutrition; index of Dickson quality.
\end{abstract}

\section{INTRODUÇÃO}

A Caatinga é um ecossistema exclusivamente brasileiro, representando $11 \%$ do território nacional e 54\% da região Nordeste (ALVES et al., 2009). Atualmente, a Caatinga vem sofrendo o efeito da antropização, em razão do desmatamento, idea lizado pela prática extrativ ista, agricultura de "sequeiro" e pecuária extensiva. A combinação dessas ações antrópicas com os fenômenos naturais ligados às mudanças climáticas expõe o semiárido a u ma ameaça ainda maior, a desertificação (LEA L et al., 2005).

Nesse cenário, a intervenção humana é inevitável, a fim de promover o reflorestamento de dessas áreas, devendo-se dar prioridade quanto à escolha das espécies vegetais a serem empregadas na recuperação de áreas degradadas, para a obtenção de resultados positivos. Essas espécies devem ser rústicas o suficiente para se 
estabelecerem em ambientes desfavoráveis, apresentando agressividade na competição com outras espé cies invasoras, facilidade de estabelecimento e rápido des envolvimento (RESENDE; KONDO, 2001).

O mulungu (Erythrina velutina Willd.) é u ma Fabaceae de porte arbóreo, atingindo alturas de 8 a $12 \mathrm{~m}$, com características de planta decídua e heliófila. É u ma espécie nativa da Caatinga, do Nordeste brasileiro e do Vale do São Francisco, sendo muito utilizada em paisagismo e na medicina popular (LORENZI; MATOS, 2008). Caracteriza-se por sua rusticidade e resistência à seca, e, devido à sua capacidade de fixar nitrogênio, é muito utilizada na recuperação de áreas degradadas. Santos et al. (2012), ao avaliarem o estabelecimento de espécies florestais nativas por meio de semeadura direta para recuperação de áre as degradadas, verificaram que o mulungu destacou-se das demais por ter apresentado maior desenvolvimento no campo.

O êxito no estabelecimento de um projeto florestal depende, entre outros fatores, da qualidade das mudas produzidas. Essas, além de resistirem às condições adversas encontradas no campo, devem desen volverse produzindo árvores com crescimento volumétrico desejável (GOMES et al., 1991).

O bom desenvolvimento das mudas ocorrerá quando o substrato for fértil e apresentar concentrações adequadas principalmente de nitrogênio, fósforo e potássio, além de outros elementos que são indispensáveis para o vigor das mudas (DIAS et al., 2006).

Na literatura são encontrados poucos trabalhos sobre fertirrigação na produção de mudas de espécies florestais nativas, e na maioria deles os resultados são divergentes, de acordo com os nutrientes e as espécies estudadas. Inoue e Sarzi (2007) avaliaram o efeito de diferentes soluções nutritivas no desenvolvimento de mudas de ipê-ro xo-de-bola (Tabebuia impetiginosa (Mart.) Standley) e não verificaram respostas significativas nos parâmetros avaliados. No entanto, Cruz et al. (2006), trabalhando com mudas de sete-cascas (Samanea inopinata (Harms) Ducke), observaram efeito significativo em decorrência do aumento nas doses de nitrogênio.

Essas divergências demonstram a importância de estudos sobre nutrição mineral no desenvolvimento de mudas de espécies arbóreas, pois a fertilização correta proporciona o melhor desenvolvimento das mudas, porém a falta ou o excesso de algum nutriente pode promover redução do crescimento das plantas (DA VIDE; FA RIA, 2008).

Diante do exposto, este trabalho foi desenvolvido com o objetivo de avaliar o efeito de diferentes concentrações de solução nutritiva via fertirrigação sobre o desenvolvimento e a qualidade de mudas de mulungu.

\section{MATERIAL E MÉTODOS}

O experimento foi realizado no período de janeiro a março de 2012, em casa de vegetação localizada na área experimental do Departamento de Ciências A mbientais e Tecnológicas, na Universidade Federal Ru ral do Semi-Árido (UFERSA), localizada no município de Mossoró, RN, situado nas coordenadas geográficas de $5^{\circ} 11^{\prime}$ S e $37^{\circ} 20^{\prime \prime} \mathrm{W}$, a $18 \mathrm{~m}$ de altitude. O clima da região, na classificação de Köppen, é do tipo BSwh (quente e seco), com precipitação pluviométrica média anual de $673,9 \mathrm{~mm}$, temperatura média de $27^{\circ} \mathrm{C}$ e umidade relativa do ar média de $68,9 \%$.

A pesquisa foi realizada com dois acessos de mulungu (Acesso 1 - Sementes pretas; Acesso 2 Sementes vermelhas), a partir de dois experimentos independentes, sendo um experimento para cada acesso, utilizando o delineamento inteiramente casualizado, com seis tratamentos e três repetições, sendo cada repetição representada por um vaso de concreto com capacidade volumétrica de $4,0 \mathrm{dm}^{3}$.

Os tratamentos foram compostos por seis concentrações de solução nutritiva $(0,25,50,75,100$ e $125 \%)$ aplicadas via fertirrigação. Utilizou-se como base para a solução nutritiva completa a formu lação usada pelo Viveiro Florestal Camará, localizado em Ibaté, SP, com condutividade elétrica de 2,12 dS. $\mathrm{m}^{-1}$. Para $100 \mathrm{~L}$ de água: $42,6 \mathrm{~g}$ de nitrato de cálcio $\left(19 \% \mathrm{Ca}^{2+} ; 15 \% \mathrm{~N}^{2} \mathrm{NO}_{3}^{-} ; 1 \%{\left.\mathrm{~N}-\mathrm{NH}_{4}-\right)}^{-} ; 15 \mathrm{~g}\right.$ de cloreto de potássio $\left(52 \% \mathrm{~K}^{+}\right.$; $\left.47 \% \mathrm{Cl}^{-}\right) ; 7,6 \mathrm{~g}$ de monoamônio fosfato (MAP) $\left.\left(11 \% \mathrm{~N}-\mathrm{NH}_{4}{ }^{-}\right) ; 26 \% \mathrm{P}_{-}-\mathrm{H}_{2} \mathrm{PO}_{4}{ }^{-}\right) ; 50 \mathrm{~g}$ de sulfato de a mônio (24\%

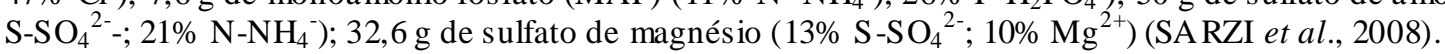

A água utilizada para o preparo das soluções foi proveniente do sistema de abastecimento do campus da UFERSA e apresentava as seguintes características: $\mathrm{pH}=8,30 ; \mathrm{CE}=0,50 \mathrm{dS} \cdot \mathrm{m}^{-1} ; \mathrm{Ca}^{2+}=3,10 ; \mathrm{Mg}^{2+}=1,10$; $\mathrm{K}^{+}=0,30 ; \mathrm{Na}^{+}=2,30 ; \mathrm{Cl}^{-}=1,80 ; \mathrm{HCO}_{3}{ }^{-}=3,00 ; \mathrm{CO}_{3}{ }^{2-}=0,20\left(\mathrm{mmol}_{\mathrm{c} .} \mathrm{L}^{-1}\right)$.

Como substrato-base para o desenvolvimento das mudas, foi utilizada amostra de solo classificado como Argis solo Vermelho-A marelo, sendo as características apresentadas na tabela 1.

Utilizou-se no estudo sementes de mulungu (Erythrina vellutina) colhidas de duas árvores-matrizes localizadas no campus da UFERSA, distantes cerca de $500 \mathrm{~m}$. Após a coleta, as sementes foram levadas ao Laboratório de Análises de Sementes (UFERSA) para realização do beneficiamento manual. Foi realizada a pesagem de 10 amostras de 100 sementes para cada acesso, obtendo-se em média $456 \mathrm{~g} / 1000$ sementes de cor preta e $496 \mathrm{~g} / 1000$ sementes de cor vermelha. 
Tabela 1. Atributos químicos e físicos do solo utilizado no experimento no desenvolvimento das mudas.

Table 1. Chemical traits regarding to fertility and physical traits of the soil used in the experiment.

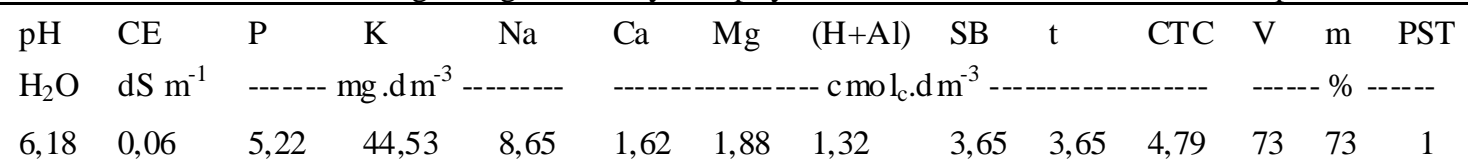

$\mathrm{pH}=$ potencial hidrogeniônico $\left(\mathrm{H}_{2} \mathrm{O}\right.$ 1:2,5); $\mathrm{CE}=$ condutividade elétrica $\left(\mathrm{H}_{2} \mathrm{O}\right.$ 1:2,5); $\mathrm{P}=$ fósforo $\left(\right.$ Melich $\left.^{-1}\right) ; \mathrm{K}=$ potássio (Melich $\left.{ }^{-1}\right)$; $\mathrm{Na}=$ sódio $\left(\right.$ Melich $\left.^{-1}\right) ; \mathrm{Ca}=$ cálcio $(\mathrm{KCl} 1 \mathrm{M}) ; \mathrm{Mg}=$ magnésio $(\mathrm{KCl} 1 \mathrm{M}) ; \mathrm{H}+\mathrm{Al}=$ acidez potencial; $\mathrm{SB}=$ soma de bases; $\mathrm{t}=$ capacidade de troca catiônica efetiva; $\mathrm{CTC}$ = capacidade de troca catiônica; $\mathrm{V}=$ saturação por bases; $\mathrm{m}$ = porcentagem de saturação por alumínio; PST $=$ porcentagem de sat uração por sódio

Antes da semeadura, realizou-se a quebra de dormência com escarificação manual na extremidade oposta à micrópila, por meio de lixa d'água n. 80, conforme diretrizes descritas por Santos et al. (2013). Em seguida, realizou-se a semeadura, utilizando-se três sementes em cada vaso, a uma profundidade de $2 \mathrm{a} 3 \mathrm{~cm}$, sendo que as sementes foram dis postas com o hilo para baixo (MATHEUS et al., 2010). O desbaste foi realizado 10 dias após a semeadura, deixando-se em cada vaso a plântula mais vigorosa. No período entre a semeadura e o desbaste, as irrigações foram realizadas utilizando-se somente água do sistema de abastecimento do campus da UFERSA, e após os desbastes realizaram-se as fertirrigações diárias, de acordo com cada tratamento, com exceção da concentração $0 \%$, na qual as plantas receberam apenas água durante todo o experimento.

As irrigações foram realizadas diariamente, sendo uma pela manhã e outra no final da tarde, aplicandose em cada irrigação o volu me de solução nutritiva suficiente para elevar a umidade do substrato à máxima capacidade de retenção de água, cessando-se a irrigação quando era perceptível início de drenagem. Assim, durante os experimentos, a quantidade de solução nutritiva aplicada variou ao longo do experimento, aplicandose os seguintes volumes diários: $100 \mathrm{~mL}$ aos 15 dias após o desbaste (DAD); $200 \mathrm{~mL}$ de 15 a $30 \mathrm{DAD} ; 500 \mathrm{~mL}$ de 30 a 50 DAD.

As plantas foram coletadas aos 60 dias após a semeadura, sendo acondicionadas em sacolas plásticas identificadas e em seguida transportadas para o Laboratório de Irrigação e Salinidade do Departamento de Ciências Ambientais e Tecnológicas da UFERSA, para serem analisadas quanto aos seguintes parâmetros de desenvolvimento: altura (ALT), número de folhas (NF), diâmetro do caule (DC), massa seca de caule (MSC), massa seca das folhas (MSF), massa seca do sistema radicial (MSR) e massa seca total (MST).

A altura foi determinada por meio de uma régua graduada em milímetros, tomando-se a medida do colo até a gema apical. O diâmetro do caule foi determinado utilizando-se um paquímetro digital, tomando-se duas medidas na região do colo e considerando a média arit mética dessas duas medidas. A área foliar foi determinada pelo método dos dois discos, seguindo o seguinte procedimento: com auxílio de um calador com diâmetro de $30 \mathrm{~mm}$, obteve-se o número máximo possível de discos do limbo, incluindo as nervuras. As amostras dos discos e o restante da folha, bem como as demais partes das plantas (caule e raízes), foram acondicionados separadamente em sacos de papel e levados à estufa de secagem, com aeração forçada e temperatura de $65^{\circ} \mathrm{C}$, onde permaneceram até atingir peso constante. A massa de matéria seca de cada parte foi determinada com auxílio de u ma balança eletrônica $(0,01 \mathrm{~g})$. A área total de cada folha (AF), e $\mathrm{m} \mathrm{cm}^{2}$, foi calculada pela fórmu la:

$$
A F=\frac{M S T F \times A T D}{M S D}
$$

em que: $\mathrm{AF}=$ área foliar; $\mathrm{MSD}=$ mass a seca dos discos; $\mathrm{ATD}=$ área total dos discos; MSTF = massa seca total das folhas.

A área foliar específica (AFE) foi determinada pela razão entre área foliar e massa seca de folhas $\left(\mathrm{cm}^{2} \cdot \mathrm{g}^{-1} \cdot \mathrm{MSF}\right)$. A razão de área foliar (RAF) foi obtida pela relação entre a área foliar e a massa seca total $\left(\mathrm{cm}^{2}\right.$.g.MST $\left.{ }^{-1}\right)$. Avaliaram-se ainda a relação altura/diâmetro do caule (ALT/DC) e o Índice de Qualidade de Dic kson (IQD) (DICKSON et al., 1960), cuja fórmu la é apresentada a seguir:

$$
I Q D=\frac{M S T}{\frac{A L T}{D C}+\frac{M S R}{M S P A}}
$$

em que: IQD = índice de qualidade de mudas de DICKSON; MST = massa seca total (g); ALT = altura de parte aérea $(\mathrm{cm}) ; \mathrm{DC}=$ diâmetro do coleto $(\mathrm{mm}) ; \mathrm{MSR}$ = massa seca da raiz $(\mathrm{g}) ; \mathrm{MSPA}=$ mass a seca da parte aérea $(\mathrm{g})$. 
Os experimentos foram analisados separadamente, sendo os dados obtidos de cada tratamento submetidos à análise de variância. Quando detectados efeitos significativos pelo teste $\mathrm{F}$, a 5\% de probabilidade, foram ajustadas equações de regressão para avaliar o efeito das concentrações de nutrientes na solução de fertirrigação sobre as variáveis estudadas As análises estatísticas foram realizadas através do Software Sisvar (FERREIRA, 2011).

\section{RES ULTADOS E DISCUSSÃO}

Na tabela 2 são apresentados os resumos das análises de variância para os dois experimentos. No experimento 1, verificou-se que não houve efeito significativo das soluções de fertirrigação para as variáveis altura de mudas (ALT), massa seca da parte aérea (MSPA), massa seca total (MST) e índice de qualidade de Dickson (IQD) ao nível de significância de $1 \%$ de probabilidade, bem como foi resposta significativa aos tratamentos para número de folhas (NF), área foliar (AF), massa seca de raiz (MSR) e relação ALT/DC ao nível de 5\% de probabilidade. Não houve resposta significativa para diâmetro do caule (DC), área foliar específica (AFE) e razão de área foliar (RAF), para as quais foram observados os valores médios de 10,82 mm, $80,33 \mathrm{~cm}^{2} \cdot \mathrm{g}^{-1} \cdot \mathrm{MSF}$ e $24,74 \mathrm{~cm}^{2} \cdot \mathrm{g} \cdot \mathrm{MST}^{-1}$, respectivamente (Tabela 2 ).

Para o experimento 2, ocorrem respostas significativa ao nível de $1 \%$ de probabilidade para as variáveis ALT, MST e IQD. Já as variáveis AF, MSPA, MSR e relação ALT/DC apresentaram resposta significativa em nível de 5\%, enquanto as demais variáveis (DC, NF, AFE e RAF) não foram afetadas pelos tratamentos aplicados, obtendo-se seguintes valores médios: $\mathrm{DC}=12,12 \mathrm{~mm}, \mathrm{NF}=40, \mathrm{AFE}=75,67 \mathrm{~cm}^{2} \cdot \mathrm{g}^{-1}$ para MSF e $\mathrm{RAF}=24,37 \mathrm{~cm}^{2} \cdot \mathrm{g}^{-1}$ para MST (Tabela 2).

Tabela 2. Resumo da análise de variância e valores médios de altura (ALT), diâmetro de caule (DC), número de folhas (NF), área foliar (AF), massa seca da parte aérea (MSPA), massa seca de raiz (MSR), massa seca total (MST), área foliar específica (AFE), razão de área foliar (RAF), re lação altura/diâmetro de caule (ALT/DC) e índice de qualidade de Dickson (IQD) em mudas de dois acessos de mulungu submetidas a diferentes níveis de fertirrigação.

Table 2. Summary of analysis of variance and medium height, stem diameter, number of leaves, leaf area, dry mass aerial part, root and total in seedlings of access Erythrina vellutina submitted different positions in the fru it and concentrations of nutrients applied by fertigation .

\begin{tabular}{|c|c|c|c|c|c|c|c|c|c|c|c|}
\hline \multirow{3}{*}{$\begin{array}{c}\text { Fontes de } \\
\text { variação }\end{array}$} & \multicolumn{11}{|c|}{ Quadrados médios } \\
\hline & ALT & $\mathrm{DC}$ & $\mathrm{NF}$ & $\mathrm{AF}$ & MSPA & MSR & MST & AFE & RAF & $\mathrm{ALT} / \mathrm{DC}$ & IQD \\
\hline & \multicolumn{11}{|c|}{ Experimento 1} \\
\hline $\mathrm{SF}$ & $174,31 * *$ & $1,72^{\mathrm{ns}}$ & $60,58 *$ & $14144,35^{*}$ & $16,85 * *$ & $0,89 *$ & $18,63 * *$ & $173,89^{\mathrm{ns}}$ & $24,23^{\mathrm{ns}}$ & $1,14 *$ & $1,57 * *$ \\
\hline Resíduo & 27,43 & 1,13 & 17,45 & 3645,23 & 2,98 & 0,05 & 3,24 & 81,21 & 23,62 & 0,23 & 0,18 \\
\hline $\mathrm{CV}(\%)$ & 14,02 & 9,82 & 13,63 & 26,44 & 15,35 & 13,18 & 19,51 & 11,22 & 19,66 & 13,790 & 16,27 \\
\hline \multirow[t]{2}{*}{ Médias } & 37,36 & 10,82 & 32,72 & 228,34 & 7,45 & 1,78 & 9,22 & 80,33 & 24,72 & 3,46 & 2,64 \\
\hline & \multicolumn{11}{|c|}{ Experimento 2} \\
\hline $\mathrm{SF}$ & $208,27 * *$ & $2,18^{\mathrm{ns}}$ & $49,28 * *$ & $12751,11 *$ & $14,37 *$ & $0,31 *$ & $17,36 * *$ & $57,62^{\mathrm{ns}}$ & $21,07^{\mathrm{ns}}$ & $1,01 *$ & $1,27 * *$ \\
\hline Resíduo & 28,50 & 0,89 & 8,92 & 962,05 & 3,21 & 0,06 & 3,14 & 31,86 & 9,42 & 0,20 & 0,18 \\
\hline $\mathrm{CV}(\%)$ & 11,15 & 7,79 & 12,57 & 11,56 & 19,29 & 14,09 & 15,96 & 7,46 & 12,60 & 11,29 & 15,91 \\
\hline Médias & 47,88 & 12,12 & 41,07 & 268,33 & 9,29 & 1,81 & 11,11 & 75,67 & 24,37 & 3,98 & 2,68 \\
\hline
\end{tabular}

$\overline{\mathrm{SF}}=$ Soluções de fertirrigação $;{ }^{\mathrm{ns}}=$ não significativo; $* *$ = significativo a $1 \%$ de probabilidade; $*$ significativo a $5 \%$ de probabilidade pelo teste F.

Conforme apresentado, não houve efeito das soluções de fertirrigação sobre as variáveis AFE e RAF (Tabela 2) em nenhum dos experimentos. A AFE expressa a espessura do tecido foliar, e a ausência na re sposta aos níveis de nutrientes estudados demonstra que as condições experimentais não limitarama expansão do limbo foliar, pois a AFE geralmente é au mentada para proporcionar maior captação da energia lu minosa e conversão em carboidratos, maximizando o crescimento das plantas. Já a RAF expressa a área foliar utilizada para a fotossíntese, sendo a razão entre área foliar e a massa seca total (BENINCASA, 2003). Dessa forma, os resultados obtidos neste trabalho significam que foi mantido um balanceamento na distribuição dos fotoassimilados nas diferentes partes da muda. 
Nas figuras 1A e 1B, são apresentados modelos de regressão ajustados para a variável altura de mudas para os dois experimentos, nas quais se verifica que os dados apresentaram melhor ajuste a modelos quadráticos, com maiores valores obtidos na solução de fertirrigação nas concentrações de 86 e $90 \%$, com valores máximos de 44,4 e 54,7 cm, respectivamente. Comparando-se esses valores com os obtidos na ausência de fertirrigação, verificaram-se aumentos de 86,5 e 58,8\%, para o acesso 1 (sementes pretas) e acesso 2 (sementes vermelhas), respectivamente.

A.

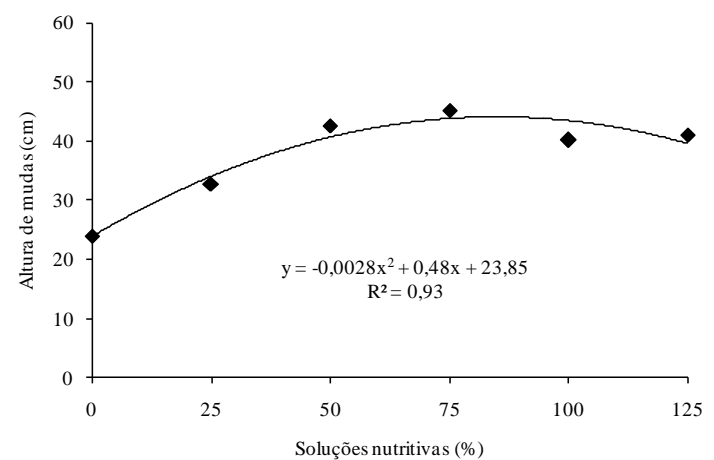

B.

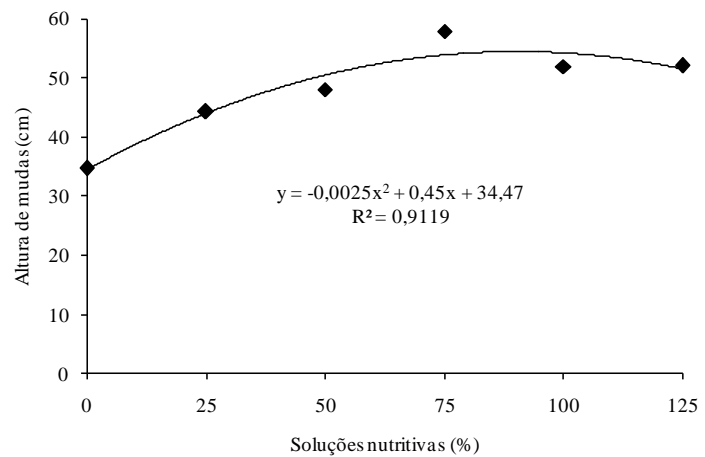

Figura 1. Dados de regressão para de altura de mudas em dois acessos de mulungu (A - acesso 1; B - acesso 2) submetidas a diferentes concentrações de nutrientes aplicados via fertirrigação.

Figure 1. Regression data for seedlings of height in two mulungu accesses (A - Access 1; B - Access 2) subjected to different concentrations of nutrients applied by fertigation.

Respostas quadráticas para níveis de adubação também foram observadas por outros autores trabalhando com diferentes espécies arbóreas, tais como Cruz et al. (2006), trabalhando com adubação nitrogenada em mudas de sete-cascas (Samanea inopinata (Harms) Ducke).

O nú mero de folhas também foi afetado de forma semelhante pelas soluções de fertirrigação para ambos os acessos, os quais apresentaram respostas quadráticas, com maiores valores ocorrendo nas concentrações de 71 e $76 \%$, com 35 e 44 folhas por muda, para os acessos 1 e 2 , respectivamente. Esses valores equivalem ao aumento de $33 \%$ (acesso 1) e $29 \%$ (acesso 2) em comparação com o número de folhas obtido na ausência de fertirrigação (Figura 2A e 2B).

A.

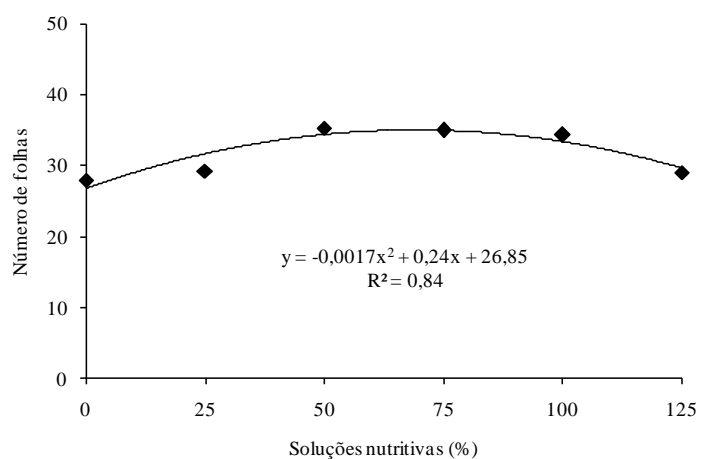

B.

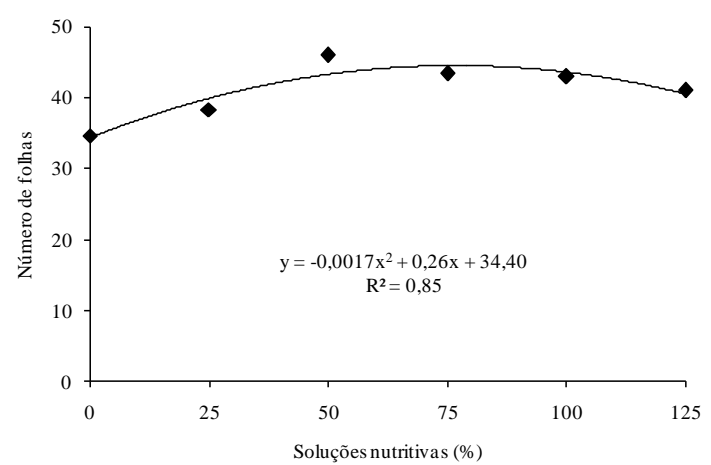

Figura 2. Dados de regressão para número de folhas em dois acessos de mulungu (A - acesso 1; B - acesso 2) submetidas a diferentes concentrações de nutrientes aplicados via fertirrigação.

Figure 2. Regression data for number of leaves in two seedling mulungu accesses (A - Access 1; B - Access 2) subjected to different concentrations of nutrients applied by fertigation.

Inoue e Sarzi (2007) avaliaram o desenvolvimento de Tabebuia impetiginosa (Mart.) Standley sob diferentes soluções de fertirrigação, aplicadas via subirrigação, e não observaram resposta significativa para essa variável, diverg indo dos resultados obtido neste trabalho. Tal divergência pode ser atribuída ao intervalo de fertirrigação utilizada por esses autores (semanal). 
Assim como observado para o número de folhas, também houve resposta quadrática dos acessos para as soluções de fertirrigação sobre a área foliar, com maiores valores de AF ocorrendo nas concentrações de 83 e $84 \%$, obtendo-se 291,1 e $328,3 \mathrm{~cm}^{2}$.planta ${ }^{-1}$, para os acessos 1 e 2, respectivamente. Ao comparar esses valores com os obtidos na ausência de fertirrigação (acesso $1=118,1 \mathrm{~cm}^{2}$; acesso $2=157,4 \mathrm{~cm}^{2}$ ), verificam-se au mentos de 146,5 e $108,5 \%$, respectivamente (Figuras $3 \mathrm{~A}$ e $3 \mathrm{~B}$ ).

A.

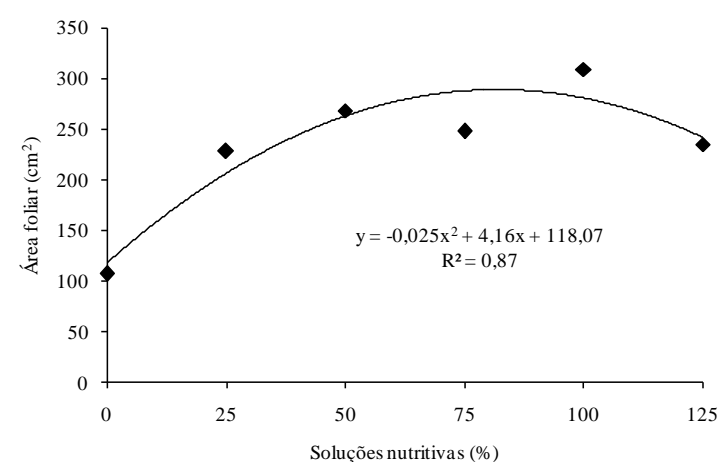

B.

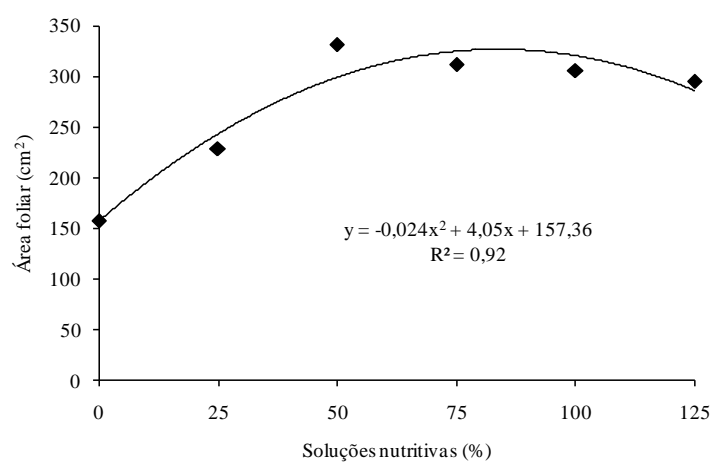

Figura 3. Dados de regressão para área foliar de mudas em dois acessos de mulungu (A - acesso 1; B acesso 2) submetidas a diferentes concentrações de nutrientes aplicados via fertirrigação.

Figure 3. Regression data for leaf area in two seedling mulungu accesses (A - Access 1; B - Access 2) subjected to different concentrations of nutrients applied by fertigation.

Analisando as variáveis NF e AF em conjunto, percebe-se que houve maior efeito da fertirrigação sobre a AF, indicando que a influência das soluções nutritivas foi mais expressiva na expansão do limbo foliar do que sobre a emissão e manutenção de novas folhas. Em estudo desenvolvido por Cordio li et al. (2014) com mudas de Khaya ivorensis sob omissão de nutrientes, os autores verificaram que o tamanho das folhas foi um dos sintomas mais visíveis em resposta à ausência de nutrientes na solução nutritiva. A AF é uma variável de grande importância na avaliação da qualidade de mudas, pois a quantidade de fotoassimilados na planta é, geralmente, proporcional à área foliar (PINTO et al., 2006).

Com relação ao acúmulo de biomassa, verifica-se que ocorreram respostas quadráticas para as variáveis MSPA, MSR e MST em a mbos os acessos. Para o acesso 1, os maiores valores ocorre ram nas concentrações de 82\% para MSPA e MSR, e 83\% para MST, em que foram obtidos valores máximos de 9,2, 2,1 e 11,5 g.planta ${ }^{-1}$, para MSPA, MSR e MST, respectivamente. Esses valores equivalem a aumento na ordem de 171, 50 e $140 \%$ em relação aos valores obtidos na ausência de fertirrigação $\left(3,4,1,4\right.$ e 4,8 g.planta ${ }^{-1}$, respectivamente) (Figura 4A).

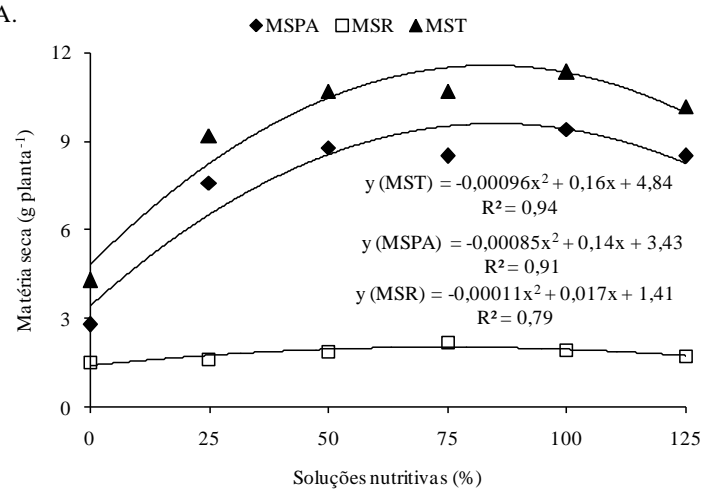

B.

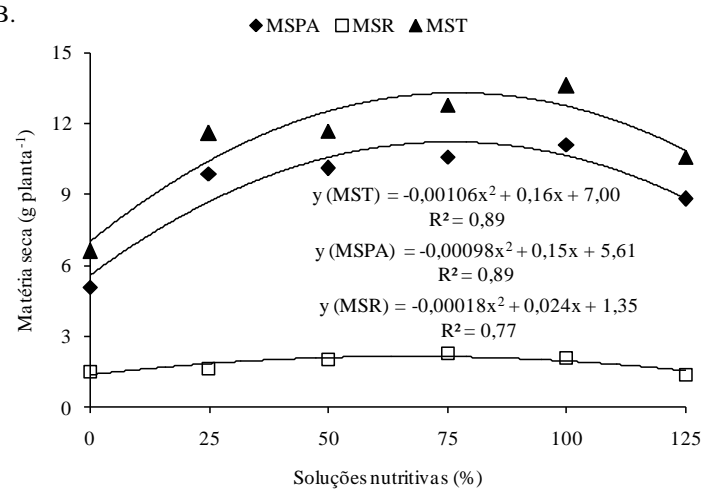

Figura 4. Dados de regressão para massa seca da parte aérea (MSPA), massa seca de raiz (MSR) e massa seca total (MST) em mudas em dois acessos de mulungu (A - acesso 1; B - acesso 2) submetidas a diferentes concentrações de nutrientes aplicados via fertirrigação.

Figure 4. Regression data for dry mass aerial part (MSPA), root (MSR) and total (MST) in two seedling mulungu accesses (A - Access 1; B - Access 2) subjected to different concentrations of nutrients applied by fertigation. 
Para o acesso 2, os maiores valores de MSPA, MSR e MST foram obtidos nas concentrações de 76, 67 e $73 \%$, ocorrendo valores máximos de $11,3,2,1$ e 12,8 $\mathrm{g}_{\text {planta }}{ }^{-1}$, respectivamente. Ao comparar esses resultados com os obtidos na ausência de fertirrigação, ocorreram aumentos de 101, 61 e $83 \%$ para as variáveis MSPA, MSR e MST, respectivamente (Figura 4B).

Na literatura são encontrados resultados divergentes quanto ao efeito da adubação sobre a produção de massa seca em mudas florestais, a exemplo de Inoue e Sarzi (2007), os quais não observaram resposta significativa em mudas de Tabebuia impetiginosa (Mart.) Standley sob diferentes soluções de fertirrigação. Em contrapartida, vários autores observaram resposta significativa e positiva da adubação sobre o desenvolvimento e produção de biomassa em diferentes espécies, a exemplo de Caione et al. (2012), Rossa et al. (2013) e Silva et al. (2013), entre outros.

A divergência entre esses resultados e os obtidos no presente trabalho demonstra a variabilidade das espécies quanto à exigência nutricional e que o mulungu é uma espécie responsiva à adubação. De acordo com Resende et al. (2000), as espécies pioneiras, a exemplo do mulungu, tendem a maior eficiência em absorver e utilizar os nutrientes, quando comparadas com as espécies secundárias e climáxicas, além do comportamento distinto entre es pécies dentro do mesmo grupo sucessional.

A relação altura/diâmetro do caule (ALT/DC) nos dois acessos foi afetada de forma quadrática em resposta ao aumento na concentração de nutrientes na solução de fertirrigação, de forma que os maiores valores ocorreram nas concentrações de 100 e 96\%, obtendo-se ALT/DC máximas de 3,8 e 4,3 para os acessos 1 e 2, respectivamente. $\mathrm{Na}$ ausência de fertirrigação, foram obtidos os menores mínimos de 2,4 e 3,0, de forma que ocorreu aumento na ordem de $58 \%$ para o acesso 1 e de $43 \%$ para o acesso 2 (Figuras 5A e 5B).

A.

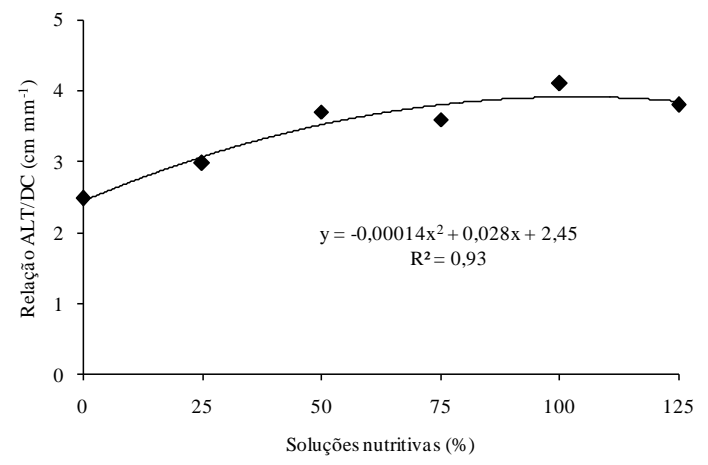

B.

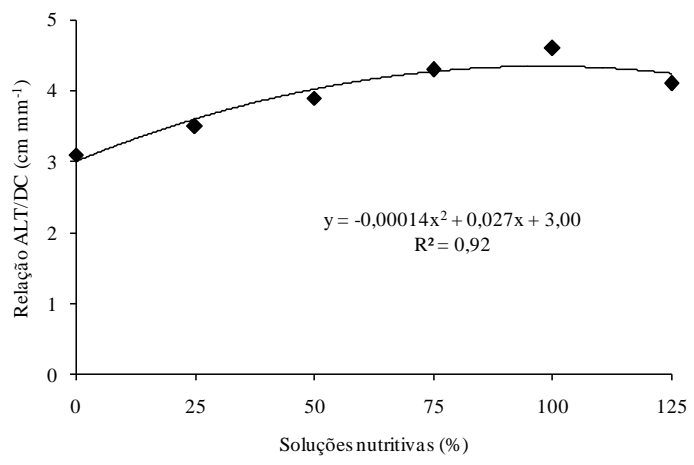

Figura 5. Dados de regressão para relação altura/diâmetro em mudas de dois acessos de mulungu (A - acesso 1; $\mathrm{B}$ - acesso 2) submetidas a diferentes concentrações de nutrientes aplicados via fert irrigação.

Figure 5. Regression data for ratio height/diameter in two seedling mulungu accesses (A - Access 1; B Access 2) subjected to different concentrations of nutrients applied by fertigation.

Comportamento semelhante ao obtido neste trabalho foi observado por Rossa et al. (2013). Trabalhando com mudas de aroeira-vermelha (Schinus terebinthifolius Raddi) e branquilho (Sebastiania commersoniana (Baill.) Smith \& Downs) submetidas a doses de fertilizante, constataram que a relação ALT/DC aumentou de maneira quadrática. Segundo esses autores, o maior crescimento em altura das mudas, que elevou o valor da relação, ocorreu em consequência da formulação com alta concentração de nitrogênio, que favoreceu o crescimento vegetativo.

De acordo com Gomes e Paiva (2004), quanto menor o quociente obtido pela relação ALT/DC, mais rustificada será a muda e maior a chance de sobrevivência e estabelecimento no local definitivo. No entanto, neste trabalho não houve efeito dos níveis de nutrientes sobre o DC, conforme descrito anteriormente. Assim, o aumento da relação ALT/DC não ocorreu em detrimento da redução no DC das mudas, como observado por Silva et al. (2013), os quais verificaram redução neste índice em mudas de cedro-doce submetidas a doses crescentes de potássio.

Por fim, assim como observado para as demais variáveis avaliadas no presente trabalho, o índice de qualidade de Dicks on (IQD) foi a fetado seguindo modelo quadrático para os dois acessos estudados. A partir dos modelos ajustados, os maiores valores foram observados nas mudas fertirrigadas com soluções nutritivas de concentrações 76 e 70\%, para as quais foram obtidos IQD máximos de 3,3 e 3,0 para os acessos 1 e 2 , respectivamente (Figuras $6 \mathrm{~A}$ e $6 \mathrm{~B}$ ). 
A.

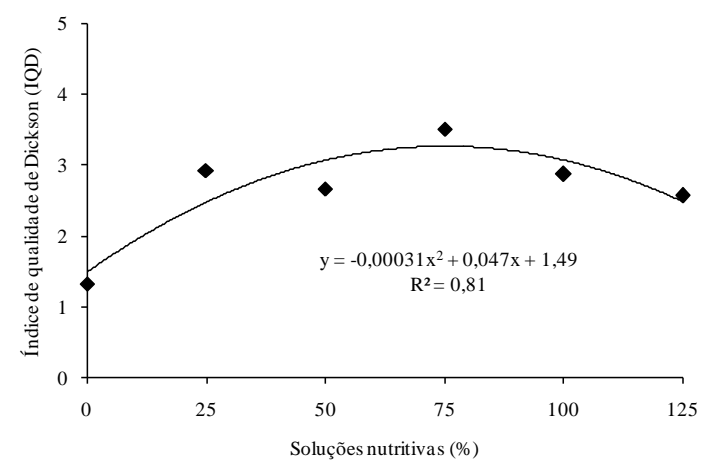

B.

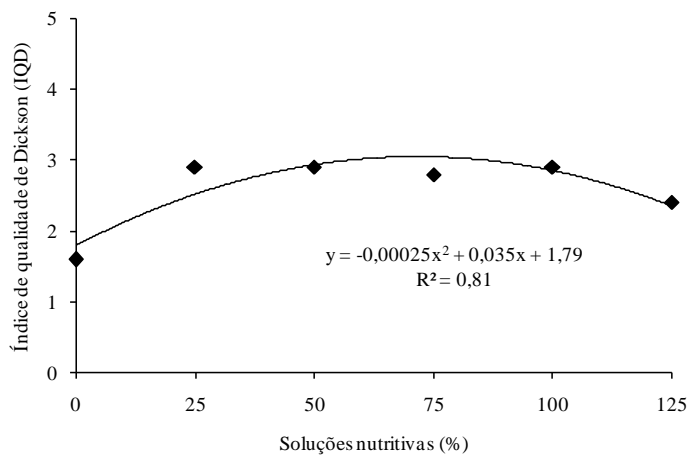

Figura 6. Dados de regressão para índice de qualidade de Dickson em mudas de dois acessos de mulungu (A acesso 1; B - acesso 2) submetidas a diferentes concentrações de nutrientes aplicados via fertirrigação.

Figure 6. Regression data for Dickson Index Quality in two seedling mulungu accesses (A - Access 1; B Access 2) subjected to different concentrations of nutrients applied by fertigation.

Em estudo desenvolvido com adubação fosfatada e inoculação micorrízica em mudas de mu lungu, Leite et al. (2014) ta mbém observaram e feito positivo da adubação sobre o IQD, obtendo mudas com IQD variando de 4,6 a 5,6, valores estes maiores que os obtidos no presente trabalho. No entanto, esses autores avaliaram as mudas aos 95 dias após a semeadura, o que favoreceu o maior desenvolvimento das mudas.

O IQD é apontado como bom indicador de qualidade de mudas, porque é utilizado para o cálculo da robustez (ALT/DC) e do equilíbrio da distribuição da bio massa (MSPA/MSRA), de forma que, quanto maior o IQD, melhor é a qualidade da muda produzida. Go mes e Paiva (2006) o consideram bastante robusto, por incluir as relações entre as variáveis morfológicas, apresentando como valor de referência 0,2 . Nes te contexto, todos os tratamentos apresentaram mudas aptas para plantio.

Os resultados obtidos neste trabalho evidenciam a importância da adubação na produção de mudas florestais de boa qualidade, corroborando outros trabalhos desenvolvidos com diferentes espécies (CRUZ et al., 2006; INOUE; SARZI, 2007; SARZI et al., 2008; ROSSA et al., 2013; SILVA et al., 2013; CORCIOLI et al., 2014). De acordo com Ceconi et al. (2007), a fase de produção de mudas é fundamental para o estabelecimento de plantas adultas bem nutridas e formadas, e a obtenção de mudas de boa qualidade exige a utilização de substrato que forneça os nutrientes necessários ao pleno desenvolvimento da planta.

\section{CONCLUS ÕES}

- Os acessos de mulungu responderam ao aumento da concentração de nutrientes na solução nutritiva de fertirrigação.

- As melhores mudas para os dois acessos de mulungu são produzidas utilizando solução nutritiva com concentração variando de 70 a $80 \%$ em relação à solução padrão.

\section{REFERÊNCIAS}

AlVES, J. J. A.; ARAÚJO, M. A.; NASCIMENTO, S. S. Degradação da Caatinga: uma investigação ecogeográfica. Revista Caatinga, Mossoró, v. 22, n. 3, p. 126 - 135, 2009.

BENINCASA, M. P. M. Análise de crescimento de plantas: noções básicas. Jaboticabal: FUNEP, 2003.41 p.

CECONI, D. E.; POLlETO, I.; LOVATO, T.; MUNIZ, M. F. B. Exigência nutricional de mudas de erva-mate (Ilex paraguariensis A. St.-Hil.) à adubação fosfatada. Ciência Florestal, Santa Maria, v. 17, n. 1, p. 25 - $32,2007$.

CORCIOLI, G.; BORGES, J. D.; JESUS, R. P. Sintomas de deficiência nutricional de macronutrientes em mudas de Khaya ivorensis cultivadas em solução nutritiva. Pesquisa Florestal Brasileira, Colombo, v. 34, n. 78, p. 159 - 164, 2014.

CRUZ, C. A. F.; PAIVA, H. N.; GUERRERO, C. R. A. Efe ito da adubação nitrogenada na produção de mudas de sete-cascas (Samanea inopinata (Harms) Ducke). Re vista Árvore, Viçosa, v. 30, n. 4, p. 537 - 546, 2006. 
DA VIDE, A. C.; FA RIA, J. M. R. Viveiros florestais. In: DA VIDE, A. C.; SILVA, E. A. A. (Eds.). Produção de sementes e mudas de es pécies florestais Lavras: UFLA, 2008. p. 83 - 122.

DIAS, E. S.; KALIFE, C.; MENEUCCI, Z. R. H.; SOUZA, P. R. Produção de mudas de espécies florestais nati vas. Campo Grande: Ed. UFMS, 2006. 59 p.

FARIA, R. A. P. G.; ALBUQUERQUE, M. C. F.; COELHO, M. F. B. Tamanho da semente e sombreamento no desenvolvimento inicial de Brosimum gaudichaudii Trécul. Revista Caatinga, Mossoró, v. 26, n. 1, p. 09 - 15 , 2013

FERREIRA, D. F. Sisvar: a computer statistical analysis system. Ciência e Agrotecnologia, Lavras, v. 35, n. 6, p. 1039 - 1042, 2011.

GOMES, J. M.; COUTO, L.; BORGES, R. C. G. Efeitos de deferentes substratos na produção de mudas de Eucalyptus grandis W.Hill ex Maiden, em “win-strip”. Re vista Ár vore, Santa Maria, v. 15, n. 1, p. 35 - $42,1991$.

GOMES, J. M; PAIVA, H. N. Viveiros Florestais: propagação sexuada. 3. ed. Viçosa: UFV, 2006.116 p. (Caderno Didático, 72).

INOUE, A. M.; SARZI, I. Produção de mudas de ipê-roxo-de-bola (Tabebuia impetiginosa (Mart.) Standley) variando as soluções de fertirrigação. Instituto Federal Série Registros, São Paulo, n. 31, p. 51 - 55, 2007.

LEA L, I. R.; SILVA, J. M. C.; TABARELLI, M.; LA CHER JÚNIOR, T. E. Mudando o curso da conservação da biodiversidade na Caatinga do Nordeste do Brasil. Re vista Megadiversidade, Belo Horizonte, v. 1, n. 1, p. 139 $-146,2005$.

LEITE, T. S.; FREITAS, R. M. O.; DOMBROSKI, J. L. D.; LEITE, M. S.; RODRIGUES, M. R. O. Crescimento e partição da biomassa de mudas de mulungu sob adubação fosfatada e inoculação micorrízica. Pesquisa Florestal Brasileira, Colombo, v. 34, n. 80, p. 407 - 415, 2014.

LORENZI, H.; MATOS, F. J. A. Plantas medicinais no Brasil: nativas e exóticas cultivadas. Nova Odessa: Instituto Plantaru m de Estudos da Flora Ltda., 2008.

MATHEUS. M. T.; GUIMARÃES, R. M.; BACELAR, M.; OLIVEIRA, S. A. S. Superação da dormência em sementes de duas espécies de Erythrina. Revista Caating a, Mossoró, v. 23, n. 3, p. 48 - 53, 2010.

PINTO, S. I. C.; FURTINI NETO, A. E.; NEVES, J. C. L.; FAQUIN, V.; MORETTI, B. S. Eficiência nutricional de clones de eucalipto na fase de mudas cultivados em solução nutritiva. Revista Brasileira de Ciência do Solo, Viçosa, v. 35, n. 2, p. 523 - 533, 2011.

RESENDE, A. V.; FURTINI NETO, A. E.; FARIA, M. R.; M UNIZ, J. A.; CURI, N. Acú mulo e eficiência nutricional de macronutrientes por espécies florestais de diferentes grupos sucessionais em resposta à fertilização fosfatada. Ciência e Agrotecnol ogia, Lavras, v. 24, n. 1, p. 160 - 173, 2000.

RESENDE, A. V.; KONDO, M. K. Leguminosas e recuperação de áreas degradadas. Informe Agropecuário, v. 22, n. 210, p. $46-56,2001$.

ROSSA, U. B.; ÂNGELO, A. C.; NOGUEIRA, A. C.; WESTPHALEN, D. J.; BASSACO, M. V. M.; MINALI, J. E. F.; BIANCHIN, J. E. Fertilizante de liberação lenta no desenvolvimento de mudas de Schinus terebinthifolius e Sebastiania commersoniana. Floresta, Curitiba, v. 43, n. 1, p. 93 - 104, 2013.

SANTOS, L. W.; COElHO, M. F. B.; MAIA, S. S. S.; SIlVA, R. C. P.; CÂNDIDO, W. S.; SILVA, A. C. Armazenamento e métodos para a superação da dormência de sementes de mulungu. Semina: Ciências Agrárias, Londrina, v. 34, n. 1, p. 171 - 178, 2013.

SANTOS, P. L.; FERREIRA, R. A.; ARA GÃO, A. G.; AMARAL, L. A.; OLIVEIRA, A. S. Estabelecimento de espécies florestais nativas por meio de semeadura direta para recuperação de áreas degradadas. Revista Árvore, Viçosa, v. 36, n. 2, p. 237 - 245, 2012.

SARZI, I.; VILLAS BÔAS, R. L.; SILVA, M. R. Composição química e aspectos morfológicos de mudas de Tabebuia chrysotricha (Standl.) produzidas em diferentes substratos e soluções de fertirrigação. Scientia Forestalis, Piracicaba, v. 36, n. 77, p. 53 - 62, 2008.

SILVA, P. M. C.; UCHÔA, S. C. P.; BARBOSA, J. B. F.; BASTOS, V. J. B.; ALVES, J. M. A.; FARIAS, L. C. Efeito do potássio e do calcário na qualidade de mudas de cedro-doce (Bombacopsis quinata). Revista Agro@mbiente On-line, Boa Vista, v. 7, n. 1, p. 63 - 69, 2013.

FLOREST A, Curitiba, PR, v. 46, n. 1, p. 47 - 55, jan. / mar. 2016.

Cavalcante, A. L. G. et al.

ISSN eletrônico 1982-4688

DOI: $10.5380 /$ rf.v46il 34888 